\title{
Imaging of Human Lens Lipids by Desorption Electrospray Ionization Mass Spectrometry
}

\author{
Shane R. Ellis, ${ }^{\mathrm{a}}$ Chunping Wu, ${ }^{\mathrm{b}}$ Jane M. Deeley, ${ }^{\mathrm{a}}$ Xiangjia Zhu, ${ }^{\mathrm{c}}$ \\ Roger J. W. Truscott, ${ }^{c}$ Marc in het Panhuis, ${ }^{a}$ R. Graham Cooks, ${ }^{b}$ \\ Todd W. Mitchell, ${ }^{\mathrm{d}}$ and Stephen J. Blanksby ${ }^{\mathrm{a}}$ \\ a School of Chemistry, University of Wollongong, Wollongong, NSW, Australia \\ ${ }^{\mathrm{b}}$ Department of Chemistry, Purdue University, West Lafayette, Indiana, USA \\ c Save Sight Institute, University of Sydney, Sydney, Australia \\ d School of Health Sciences, University of Wollongong, Wollongong, NSW, Australia
}

\begin{abstract}
The lipid composition of the human lens is distinct from most other tissues in that it is high in dihydrosphingomyelin and the most abundant glycerophospholipids in the lens are unusual 1-O-alkyl-ether linked phosphatidylethanolamines and phosphatidylserines. In this study, desorption electrospray ionization (DESI) mass spectrometry-imaging was used to determine the distribution of these lipids in the human lens along with other lipids including, ceramides, ceramide-1-phosphates, and lyso 1-O-alkyl ethers. To achieve this, $25 \mu \mathrm{m}$ lens slices were mounted onto glass slides and analyzed using a linear ion-trap mass spectrometer equipped with a custom-built, 2-D automated DESI source. In contrast to other tissues that have been previously analyzed by DESI, the presence of a strong acid in the spray solvent was required to desorb lipids directly from lens tissue. Distinctive distributions were observed for $[\mathrm{M}+\mathrm{H}]^{+}$ ions arising from each lipid class. Of particular interest were ionized 1-O-alkyl phosphatidylethanolamines and phosphatidylserines, PE (18:1e/18:1), and PS (18:1e/18:1), which were found in a thin ring in the outermost region of the lens. This distribution was confirmed by quantitative analysis of lenses that were sectioned into four distinct regions (outer, barrier, inner, and core), extracted and analyzed by electrospray ionization tandem mass spectrometry. DESI-imaging also revealed a complementary distribution for the structurally-related lyso 1-O-alkyl phosphatidylethanolamine, LPE (18:1e), which was localized closer to the centre of the lens. The data obtained in this study indicate that DESI-imaging is a powerful tool for determining the spatial distribution of human lens lipids. (J Am Soc Mass Spectrom 2010, 21, 2095-2104) (c) 2010 American Society for Mass Spectrometry
\end{abstract}

$\mathrm{T}$ The lens consists of concentric layers of crescent shaped fiber cells resulting in a tightly packed arrangement of cell membranes in which the major components are integral membrane proteins, phospholipids and cholesterol (Chol) [1]. The phospholipid composition of the human lens differs from that of other animals in that it is unusually high in dihydrosphingomyelin (DHSM) [2, 3]. Recent work has shown that human lenses are also abundant in etherlinked phospholipids, in particular 1-O-alkyl phosphatidylethanolamine (PE) and phosphatidylserine (PS) $[3,4]$. DHSMs represent more than $40 \%$ of all human lens phospholipids [5, 6], while PE and PS lipids represent $15 \%$ and $8 \%$, respectively, with $1-O$-alkyl lipids making up more than half of the total contribution from each of the latter two classes [3]. In an effort to understand the function of these ether-linked phospholipids, we have initiated a study on their distribution throughout the lens using mass spectrometry imaging.

Address reprint requests to Dr. S. Blanksby, School of Chemistry, University of Wollongong, NSW 2522, Australia. E-mail: blanksby@uow.edu.au and Dr. T. Mitchell, School of Health Sciences, University of Wollongong, NSW 2522, Australia. E-mail: toddm@uow.edu.au
Matrix-assisted laser desorption ionization (MALDI) is a well established technique for the analysis of individual molecular lipids from complex biological mixtures including lens tissue typically obtained from model animals [7, 8]. The development of MALDIimaging has also allowed the spatial distributions of lipids within biological tissue to be investigated [9] including imaging of porcine [10] and human lens lipids [11]. In the latter study, Deeley et al. imaged the distributions of the two most abundant lens lipids, SM (d18:0/16:0) and SM (d18:0/24:1), as well as the corresponding ceramides in human lenses of different ages [11]. An annular distribution of the DHSM lipids was observed in the outer regions of the lens and this effect became more pronounced with age. Interestingly, related ceramides were primarily found in the nucleus and were absent from younger lenses suggesting a possible product-precursor relationship exists between the DHSMs and their ceramide homologues [11]. In addition to lipid-imaging, several studies have utilized MALDI-imaging for visualizing the distribution of ocular proteins, including Aquaporin- 0 and $\alpha$-crystallin as well as their truncation products [12-15]. 
Although a very useful technique, MALDI analysis of lipids from biological samples suffers two disadvantages: (1) along with introducing an additional sample preparation step, the application of the matrix must be done so as to result in a homogeneous distribution to minimize any "sweet spot" effects (it should be noted that application of the matrix by sublimation can ameliorate this effect [16]), and (2) in positive ion mode the mass spectra are dominated by the choline-containing lipids (phosphatidylcholine and sphingomyelin) making the detection of other less abundant lipids such as PE and PS difficult [8]. Murphy et al. have also suggested that rapid decomposition of $[\mathrm{M}+\mathrm{H}]^{+}$ions of acidic phospholipids such as PE and PS further complicates the detection of these lipid classes [9].

Desorption electrospray ionization (DESI) is an alternative surface desorption and ionization approach developed in one of our laboratories in 2004 that allows the soft ionization of analytes direct from substrates (including tissue sections) with minimal sample preparation $[17,18]$. The ability to raster across a sample whilst continuously acquiring mass spectra has led to the development of DESI as an ambient mass spectrometric imaging technique [19]. While the spatial resolution of DESI $(\sim 200 \mu \mathrm{m}$ [19]) is lower than that of MALDI (50-100 $\mu \mathrm{m}[9,11])$, DESI requires no matrix thus minimizing the possibility of inhomogeneity arising from sample preparation. DESI has also been shown to be effective for the detection of a wide range of lipid classes [20-22] making it ideal for lipid-imaging applications (see discussion in reference [23]). DESI-imaging has previously been demonstrated for determining the spatial distributions of lipids from a variety of tissue types including rat brain [19], porcine and rabbit adrenal glands [24], tumor/non tumor regions of dog bladder tissue [20], as well as drug localization of pre-dosed clozapine in rat brain $[25,26]$. The work presented here demonstrates the first application of DESI-imaging to the human lens and reveals the localization of several abundant lens lipids.

\section{Experimental}

\section{Materials}

Human lens sections were sourced from the Sydney Lions Eye Bank, (Sydney, NSW, Australia). All work was approved by the human research ethics committees at the University of Wollongong (HE 99/001) and University of Sydney (\#7292). Lenses were sliced as coronal sections (i.e.; a vertical plane from head to foot and parallel to the shoulders) using a cryostat (Leica 1720 , Wetzlar, Hesse, Germany) at $-20^{\circ} \mathrm{C}$ at a thickness of ca. $25 \mu \mathrm{m}$ and thaw-mounted onto glass slides. Note that coronal sections would be expected to give a near circular slice however when analyzed the slices had an oval shape due to slight compression during slicing. All phospholipid internal standards were purchased from Avanti Polar Lipids (Alabaster, AL, USA). Cholesterol standard was obtained from purchased from Sigma Aldrich (Castle Hill, NSW, Australia). Methanol (HPLC grade), chloroform (HPLC grade) and acetic acid (AR grade) were used for lipid extraction and were all purchased from Crown Scientific (Sydney, NSW, Australia). Methanol (HPLC grade; Mallinckrodt Baker Inc., Phillipsburg, NJ, USA), Milli-Q water (Millipore, Billerica, MA, USA) and hydrochloric acid $(33 \%, \mathrm{~J}$. T. Baker, Phillipsburg, NJ, USA) were used for DESI spray solutions.

\section{Desorption Electrospray Ionization Mass Spectrometry (DESI-MS)}

DESI-MS was performed on a ThermoFinnigan LTQ mass spectrometer (ThermoScientific, San Jose, CA) coupled to a custom built, 2-D automated DESI source as described elsewhere [27]. The solvent was delivered through a fused silica inner capillary (i.d. $50 \mu \mathrm{m}$, o.d. $150 \mu \mathrm{m})$ (Polymicro Technologies, Phoenix, AZ, USA) and the nebulizing gas $\left(\mathrm{N}_{2}\right.$ at $\left.150 \mathrm{psi}\right)$ through the outer capillary (I.D. $250 \mu \mathrm{m}$, O.D. $350 \mu \mathrm{m}$ ). Methanol:water $(4: 1 \mathrm{vol} / \mathrm{vol})+0.05 \%(\mathrm{wt} / \mathrm{vol})$ hydrochloric acid was used as the spray solvent at a flow rate of $3 \mu \mathrm{L} \cdot \mathrm{min}^{-1}$. The optimized DESI source geometry used an incident emitter-surface angle of $55^{\circ}$, a collection angle (sampleinlet angle) of $\sim 10^{\circ}$ and a short emitter-sample distance of 1-2 $\mathrm{mm}$. The spray voltage was set to $5 \mathrm{kV}$, tube lens and capillary voltages were 110 and $5 \mathrm{~V}$, respectively, and the capillary was heated to $275^{\circ} \mathrm{C}$. The ion injection time was $450 \mathrm{~ms}$, while 2 microscans were summed for each spectrum, giving an acquisition time of $1.02 \mathrm{~s}$. Automatic gain control (AGC) was turned off for all experiments. General CID conditions utilized a collision energy of 25-30 (arbitrary units) and an isolation width of 1.5 Da. Exact mass measurements were performed on a hybrid LTQ-Orbitrap (ThermoScientific, San Jose, CA) operating at a mass resolution of 100,000. The LTQOrbitrap was fitted with an identical DESI source and the lens slice was analyzed as previously described with the exception that a standard PC (16:0/18:0) was doped into the spray solution at a concentration of $0.5 \mathrm{ppm}$ to provide an $[\mathrm{M}+\mathrm{H}]^{+}$ion at $m / z 762.60073$ for use as the lock mass. For cholesterol detection $3 \times 2 \mu \mathrm{L}$ aliquots of a $200 \mathrm{ng} \cdot \mathrm{mL}^{-1}$ solution of cholesterol in 1:1 methanol: chloroform (vol/vol) were deposited onto a Teflon coated glass slide (Omnislide; Prosolia Inc.; Indianapolis, IN, USA) and allowed to air dry before analysis.

\section{Image Acquisition}

Lens slices were mounted on glass slides and placed on the sample stage, which was moved at a constant velocity of $196 \mu \mathrm{m} . \mathrm{s}^{-1}$ with steps of $200 \mu \mathrm{m}$ between each successive line scan to give a pixel size of $200 \times$ $200 \mu \mathrm{m}^{2}$. Each line scan was acquired as a separate file. Once the whole lens had been analyzed, in-house software was used to convert Xcalibur mass spectral 
files into the required format for image generation in BioMap (freeware, http://www.maldi.msi.org/). The maximum and minimum threshold intensities were then adjusted to improve the contrast in the ion images.

\section{Lipid Extraction}

Whole lenses (from 52-y and 75-y-old individuals) were sectioned into outer, barrier, inner, and core regions by the methods previously described by Heys et al. [28] and then placed in pre-weighed vials. The dimensions used to define each region are shown in Figure 1. Lens sections were homogenized by first freezing the lens in liquid nitrogen $(10-20 \mathrm{~mL})$ in a mortar and then pulverizing the tissue. A mixture of internal standards in methanol consisting of $40 \mu \mathrm{M}$ PC (19:0/19:0), $40 \mu \mathrm{M} \mathrm{SM}$

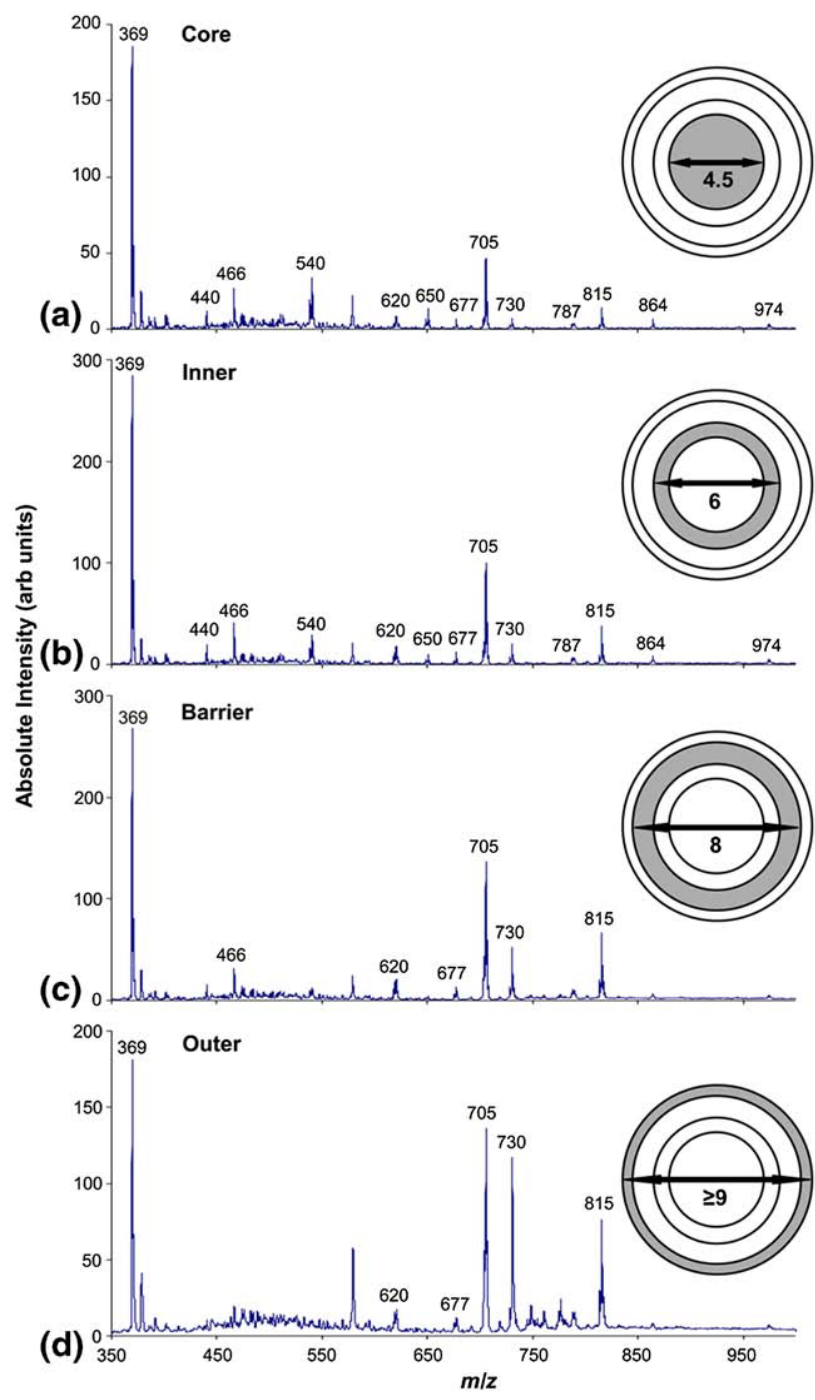

Figure 1. DESI spectra averaged over different regions of a human lens section obtained from a $41 \mathrm{y}$-old individual. The following regions were selected using the region of interest (ROI) tool in the BioMap imaging software: (a) core region, (b) inner region, (c) barrier region, (d) outer region. The relative dimensions used to select each region are shown in the schematic adjacent to the corresponding spectrum. (d18:0/12:0) and $25 \mu \mathrm{M}$ PE (17:0/17:0) was then added to the pulverized tissue at $1400 \mu{\mathrm{L} . \mathrm{g}^{-1}}^{-1}$ (tissue).

Lipids were extracted from lens section homogenates using a modified Folch method [29] with aqueous acetic acid substituted for aqueous sodium chloride. In brief, chloroform:methanol (2:1 vol/vol) containing 0.01\% $\mathrm{wt} /$ vol butylated hydroxytoluene (BHT) as an antioxidant was added to the lens section homogenates at a ratio of 20:1 solvent to tissue weight (vol:wt) and the homogenates rotated overnight at $4{ }^{\circ} \mathrm{C}$. Aqueous acetic acid $(20 \mathrm{mM})$ was then added at a ratio of $8: 4: 3$ chloroform:methanol:acetic acid $(20 \mathrm{mM})$ and the samples centrifuged at $2000 \mathrm{~g}$ for $5 \mathrm{~min}$. The organic layer was retained and 2:1 chloroform:methanol $(2 \mathrm{~mL})$ added to the aqueous phase and the process repeated. The combined organic extracts were washed with aqueous acetic acid $(1 \mathrm{~mL}, 20 \mathrm{mM})$. The organic layer was retained and then evaporated to dryness under a stream of nitrogen. Finally, samples were reconstituted in $500-1000 \mu \mathrm{L}$ of chloroform:methanol (1:2 vol/vol) and stored at $-80^{\circ} \mathrm{C}$ until analysis.

\section{Quantitation of 1-O-Alkyl PE by Electrospray Ionization Mass Spectrometry (ESI-MS)}

Lipid extracts were diluted to an estimated final concentration of $40 \mu \mathrm{M}$ using chloroform:methanol (1:2 $\mathrm{vol} / \mathrm{vol}$ ) then analyzed in positive ion mode using a Waters QuattroMicro triple quadrupole mass spectrometer (Waters, Manchester, UK) with a z-spray ion source. Typical instrument settings were a flow rate of $10 \mu \mathrm{L} . \mathrm{min}^{-1}$, capillary voltage of $3 \mathrm{kV}$, source temperature of $80^{\circ} \mathrm{C}$, desolvation temperature of $120^{\circ} \mathrm{C}$, and a cone voltage of $50 \mathrm{~V}$. Nitrogen was used as the drying gas at a flow rate of $320 \mathrm{~L} \cdot \mathrm{h}^{-1}$. All lipids with the phosphoethanolamine head group were identified and quantified by a neutral loss scan of $141 \mathrm{Da}$ as described previously [3].

\section{Results and Discussion}

\section{Lens Lipids Detected by DESI-MS}

Throughout the investigation, the composition of the spray solution was found to be the most critical parameter to allow the detection of lipids direct from lens tissue by DESI-MS. It was found that a spray solvent consisting of 4:1 methanol:water ( $\mathrm{vol} / \mathrm{vol})+0.05 \%$ (wt/vol) hydrochloric acid allowed the detection of a wide range of lens lipids. Weaker acids including acetic, formic and trifluoroacetic acid were also used, however these resulted in very little or no detection of ionized lipids. The necessity of a strong acid in the spray solution is surprising as previous DESI-imaging data performed on a variety of other tissue types have allowed the detection of lipids in both positive and negative mode using simple methanol/water or acetonitrile/water mixtures with no doping of acids required $[20,24,30,31]$. The need for a relatively harsh spray 
composition for the human lens may be a consequence of the tightly compacted structure of the fiber cells and their relatively high protein content compared to other tissue types. For comparison, human lenses can have protein-to-lipid ratios as high as 5.0 (depending on the region of the lens sampled and the age of the individual) [32], while rat brain has a ratio of only ca. 2.14 [33]. The latter tissue has previously been analyzed by DESI-MS using simple methanol:water mixtures for the spray solvent [19]. Additionally, the tight interaction between membrane lipids and proteins in the human lens has been observed in the crystal structure of lens specific Aquaporin-0 and may further rationalize the difficulties in desorbing lipids from this tissue [34]. It is interesting to note that lipids were only detected from lens tissue when the DESI spray was observed to physically disrupt the structure of the tissue section during analysis. Fewer ions were detected from the innermost (core) region of the lens. It is not clear if this is an accurate representation of the abundance of lipids in this region or an artifact of the DESI process whereby the relatively soft DESI technique is unable to desorb lipids from the centre of the lens where there is a higher protein concentration [35]. Nevertheless, similar results have been obtained for specific lipids using MALDIimaging and quantitative analysis of human lens sections [11]. This prompted us to undertake a parallel quantitative investigation (see later).

Figure 1 shows positive ion DESI spectra obtained by averaging the data acquired over each of the following regions in a section from a 41 y-old lens; outer, barrier, inner and core. The dimensions used to define each region are shown on the right of the figure. All lipids were observed as $[\mathrm{M}+\mathrm{H}]^{+}$ions with the exception of cholesterol which was observed as the $\left[\mathrm{M}+\mathrm{H}-\mathrm{H}_{2} \mathrm{O}\right]^{+}$ ion. The four most abundant ions were detected with nominal $\mathrm{m} / \mathrm{z}$ values of $369,705,730$ and 815 . The $\mathrm{m} / \mathrm{z} 369$ ion was tentatively assigned as the $\left[\mathrm{M}+\mathrm{H}-\mathrm{H}_{2} \mathrm{O}\right]^{+}$ion of cholesterol based on (1) prior observation which shows that cholesterol is an abundant component of the human lens [3] and (2) the previous observation of dehydrated cholesterol in MALDI studies of tissue sections [9]. The $m / z 369$ ion was only observed with hydrochloric acid doped into the spray solution suggesting the presence of the strong acid assists in the dehydration process. Figure 2 shows CID spectra of the $\mathrm{m} / \mathrm{z} 369$ ion observed from the lens and that generated by DESI from a cholesterol standard. There is excellent

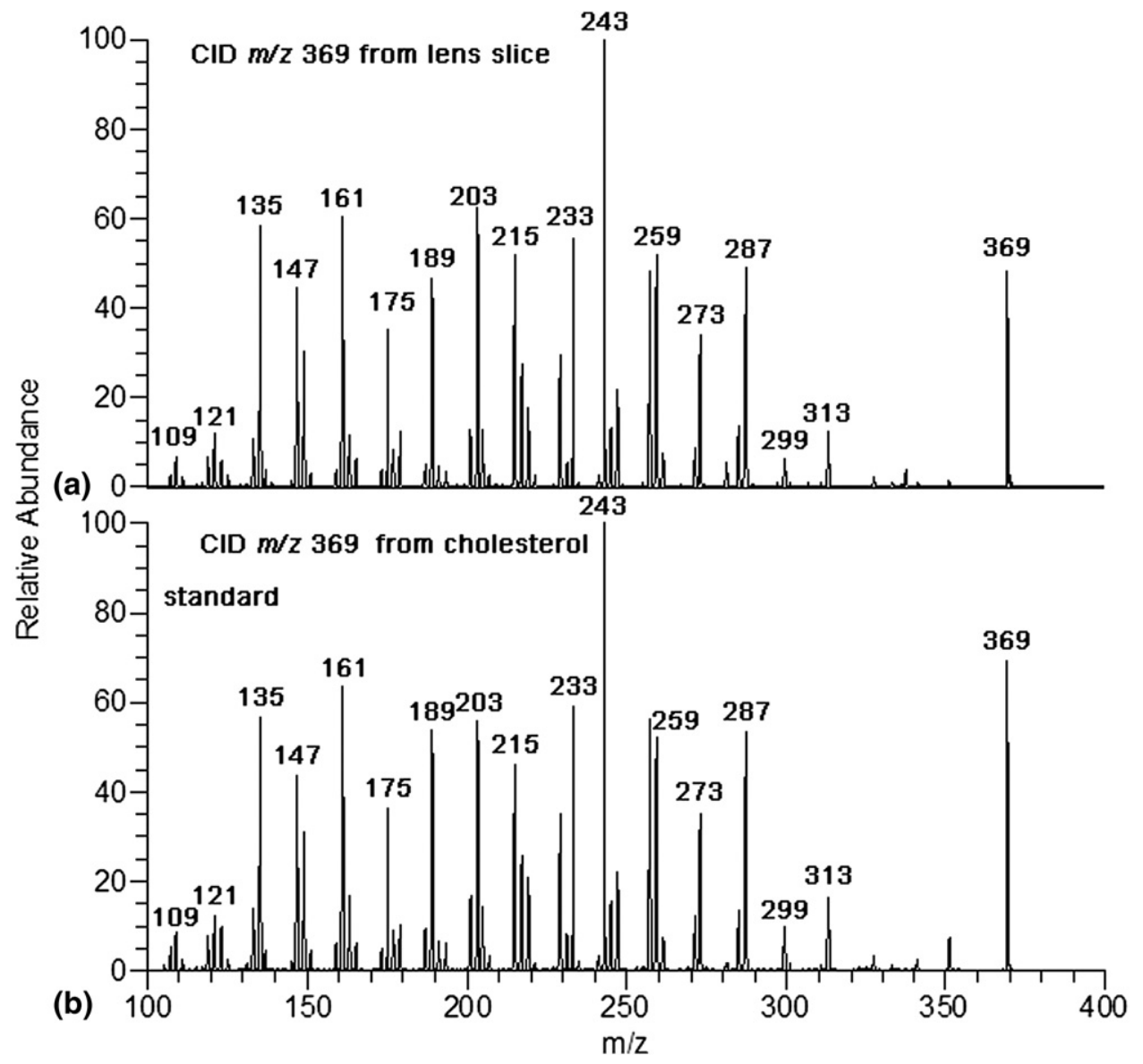

Figure 2. (a) CID of the $\mathrm{m} / \mathrm{z} 369$ ion obtained from a 41 y-old human lens slice and (b) CID of an $\mathrm{m} / \mathrm{z}$ 369 ion obtained from a cholesterol standard. An aliquot $(6 \mu \mathrm{L})$ of a $200 \mathrm{ng} \cdot \mathrm{mL}^{-1}$ solution of cholesterol in 1:1 $\mathrm{MeOH}: \mathrm{CHCl}_{3}$ (vol/vol) was deposited onto a PTFE printed slide. CID spectra were recorded using a collision energy of 27 (arbitrary units) with an isolation width of $1.5 \mathrm{Da}$. 
agreement both in the masses of product ions and their relative abundances providing strong evidence for the assignment of the $m / z 369$ ion as [Chol $\left.+\mathrm{H}-\mathrm{H}_{2} \mathrm{O}\right]^{+}$. It is also possible that the $\mathrm{m} / \mathrm{z} 369$ ion could arise from decomposition of the ester moiety of a cholesterol esters via cis-elimination [36]. Such processes however, normally require high temperatures and thus are unlikely to be significant under the conditions of this analysis. Direct in situ analysis of intact cholesterol by DESI-MS has previously been achieved using the "reactive DESI" technique whereby betaine aldehyde is doped into the spray [22]. This reagent could not be applied here as it is unstable under the spray conditions required for lens analysis.

The ions at $m / z 705$ and 815 (Figure 1) have nominal masses that correspond to the protonated forms of SM (d18:0/16:0) and SM (d18:0/24:1), respectively. As these are the two most abundant phospholipids in the human lens, the peaks at $m / z 705$ and 815 are assigned to these two dihydrosphingomyelins $[3,37]$. Collision induced dissociation (CID) of these two ions did not yield any structural information, as the characteristic ion at $\mathrm{m} / \mathrm{z}$ 184 that is usually used to identify protonated sphingomyelins and phosphatidylcholines is below the low mass cut-off of the LTQ ion trap mass spectrometer under the operating conditions used. The ion at $\mathrm{m} / \mathrm{z} 730$ has the same nominal mass as the protonated 1-O-alkyllinked phospholipid, PE (18:1e/18:1), previously identified as the most abundant glycerophospholipid in the human lens [4]. CID of this ion produced a fragment ion at $m / z 589$ corresponding to the neutral loss of the phosphoethanolamine headgroup (141 Da, data not shown), thus the $m / z 730$ ion is assigned as protonated PE (18:1e/18:1). The ions at $\mathrm{m} / \mathrm{z} 440$ and 466 are assigned as the protonated lyso phospholipid analogues of the 1-O-alkyl PE, namely LPE (16:0e) and LPE (18:1e) respectively, based on their nominal masses and their previous observation in human lens tissue [37].

Table 1 shows the results of exact mass measurements for the most abundant DHSMs, PCs and 1-Oalkyl PEs acquired by DESI-MS analysis from a lens section on a hybrid LTQ-Orbitrap instrument (ion transmission on the LTQ-Orbitrap was tuned to the critical $m / z$ 700-850 region and consequently low mass lipids were not observed). The exact mass measurements are in excellent agreement with the assigned structures of the abundant lens phospholipids providing further evidence that the $m / z 705,730$, and 815 ions arise from the assigned lipids. While exact mass measurements do not distinguish between isomeric lipids, previous work by some of us has included detailed structure elucidation of human lens lipids and thus we are confident in the assigned structures [4, 38].

Further analysis of the exact mass data showed the presence of an ion isobaric with $[\mathrm{PE}(18: 1 \mathrm{e} / 18: 1)+\mathrm{H}]^{+}$at $\mathrm{m} / \mathrm{z} 730.61,072$, which can be assigned as protonated dihydroceramide-1-phosphate 24:1 ([Cer1P (d18:0/24:1) + $\mathrm{H}]^{+}$) as recently identified in the human lens by Estrada et al. using ${ }^{31} \mathrm{P}$ NMR and MALDI-MS techniques [37].
Table 1. Exact mass measurements recorded using an LTQOrbitrap mass spectrometer of $\left[\mathrm{M}+\mathrm{H}^{+}\right.$ions detected via DESI-MS of a human lens section. No lens-related ions below $\mathrm{m} / \mathrm{z} 700$ were observed on the LTQ-Orbitrap

\begin{tabular}{|c|c|c|}
\hline $\begin{array}{l}\text { Observed mass } \\
\qquad(\mathrm{m} / \mathrm{z})\end{array}$ & $\begin{array}{c}\text { Assigned structure } \\
\text { (elemental composition) }\end{array}$ & $\begin{array}{c}\Delta \\
(\mathrm{ppm})\end{array}$ \\
\hline 703.57483 & $\begin{array}{l}{[\mathrm{SM}(\mathrm{d} 18: 1 / 16: 0)+\mathrm{H}]^{+}} \\
\quad\left(\mathrm{C}_{39} \mathrm{H}_{80} \mathrm{~N}_{2} \mathrm{O}_{6} \mathrm{P}\right)\end{array}$ & -0.034 \\
\hline 704.55898 & $\begin{array}{l}{[\mathrm{PE}(16: 0 \mathrm{e} / 18: 1)+\mathrm{H}]^{+}} \\
\quad\left(\mathrm{C}_{39} \mathrm{H}_{79} \mathrm{NO}_{7} \mathrm{P}\right)\end{array}$ & 0.157 \\
\hline 705.59051 & $\begin{array}{l}{[\mathrm{SM}(\mathrm{d} 18: 0 / 16: 0)+\mathrm{H}]^{+}} \\
\quad\left(\mathrm{C}_{39} \mathrm{H}_{82} \mathrm{~N}_{2} \mathrm{O}_{6} \mathrm{P}\right)\end{array}$ & 0.009 \\
\hline 730.57542 & $\begin{array}{l}{[\mathrm{PE}(18: 1 \mathrm{e} / 18: 1)+\mathrm{H}]^{+}} \\
\quad\left(\mathrm{C}_{41} \mathrm{H}_{81} \mathrm{NO}_{7} \mathrm{P}\right)\end{array}$ & 1.233 \\
\hline 730.61072 & $\begin{array}{l}{[\text { Cer1P }(\mathrm{d} 18: 0 / 24: 1)+\mathrm{H}]^{+}} \\
\quad\left(\mathrm{C}_{42} \mathrm{H}_{85} \mathrm{NO}_{6} \mathrm{P}\right)\end{array}$ & -0.253 \\
\hline 748.54800 & $\begin{array}{l}{[\mathrm{PS}(16: 0 \mathrm{e} / 18: 1)+\mathrm{H}]^{+}} \\
\quad\left(\mathrm{C}_{40} \mathrm{H}_{79} \mathrm{NO}_{9} \mathrm{P}\right)\end{array}$ & -0.933 \\
\hline 760.58513 & $\begin{array}{l}{[\mathrm{PC}(16: 0 / 18: 1)+\mathrm{H}]^{+}} \\
\quad\left(\mathrm{C}_{42} \mathrm{H}_{83} \mathrm{NO}_{8} \mathrm{P}\right)\end{array}$ & -0.060 \\
\hline 774.56623 & $\begin{array}{l}\text { [PS }(18: 1 \mathrm{e} / 18: 1)+\mathrm{H}]^{+} \\
\quad\left(\mathrm{C}_{42} \mathrm{H}_{81} \mathrm{NO}_{9} \mathrm{P}\right)\end{array}$ & 2.429 \\
\hline 787.68616 & $\begin{array}{l}{[\mathrm{SM}(\mathrm{d} 18: 1 / 22: 0)+\mathrm{H}]^{+}} \\
\quad\left(\mathrm{C}_{45} \mathrm{H}_{92} \mathrm{~N}_{2} \mathrm{O}_{6} \mathrm{P}\right)\end{array}$ & -0.107 \\
\hline 813.68453 & $\begin{array}{l}{[\mathrm{SM}(\mathrm{d} 18: 1 / 24: 1)+\mathrm{H}]^{+}} \\
\quad\left(\mathrm{C}_{47} \mathrm{H}_{94} \mathrm{~N}_{2} \mathrm{O}_{6} \mathrm{P}\right)\end{array}$ & 0.154 \\
\hline 815.70005 & $\begin{array}{l}{[\mathrm{SM}(\mathrm{d} 18: 0 / 24: 1)+\mathrm{H}]^{+}} \\
\quad\left(\mathrm{C}_{47} \mathrm{H}_{96} \mathrm{~N}_{2} \mathrm{O}_{6} \mathrm{P}\right)\end{array}$ & -0.005 \\
\hline
\end{tabular}

The analogous ceramide phosphate containing a 16:0 fatty amide, Cer1P (d18:0/16:0), is also present as the protonated lipid at $m / z 620$ in the DESI spectra shown in Figure 1. The high-resolution spectra show the [Cer1P $(\mathrm{d} 18: 0 / 24: 1)+\mathrm{H}]^{+}$ion has a relative abundance typically $10-20 \%$ that of the protonated PE (18:1e/18:1) (data not shown). These data along with the following evidence suggests that the distribution of the nominal mass $\mathrm{m} / \mathrm{z} 730$ (see later) is dominated by [PE (18:1e/ $18: 1)+\mathrm{H}]^{+}$; (1) the CID spectrum of the ion at $\mathrm{m} / z 730$ reveals a lower abundance of the neutral loss of $98 \mathrm{Da}$ (arising from loss of $\mathrm{H}_{3} \mathrm{PO}_{4}$ from the Cer1P) relative to the neutral loss of $141 \mathrm{Da}$ (arising from the PE headgroup); and (2) the abundance of [Cer1P (d18:0/16:0) + $\mathrm{H}^{+}$at $m / z 620$ is already relatively low and this lipid is expected to be more abundant than its longer chain homologue, Cer1P (d18:0/24:1) based on the trend observed for the structural homologues DHSM, ceramides, and lactosylceramides (see later).

The ions at $m / z 540$ and 650 in Figure 1 are assigned to $[\mathrm{Cer}(\mathrm{d} 18: 0 / 16: 0)+\mathrm{H}]^{+}$and $\left[\mathrm{Cer}(\mathrm{d} 18: 0 / 24: 1)+\mathrm{H}^{+}\right.$, respectively. These ceramides have previously been identified in human lens tissue by MALDI-MS and ${ }^{31} \mathrm{P}$ NMR $[11,37]$. In addition, two low abundance ions are observed at $m / z 864$ and 974 (Figure 1). These two ions are separated by $110 \mathrm{Da}$, which coincides with the mass difference between a 16:0 and 24:1 fatty amide, and are consistent with protonated glycosphingolipids containing a sphinganine backbone and either a $16: 0$ or $24: 1$ fatty amide. These two lipids are tentatively assigned as the lactosyldihydroceramides, LacCer (d18:0/16:0) and 
LacCer (d18:0/24:1), as they have previously been reported as the two most abundant glycosphingolipids in the human lens $[39,40]$.

Table 2 shows all lens lipids detected by DESI-MS where the assignment is based on previous lens lipid identification studies $[3,4,37,39,40]$ and, where possible, confirmed by CID and exact mass measurements. Compared with a recent study of human lens phospholipids and sphingolipids using shotgun lipodomics [3], ca. 50\% of lipids with concentrations greater than $20 \mathrm{nmol} / \mathrm{g}$ wet tissue were detected and confidently assigned in our positive ion DESI-MS analysis. In all cases, the most abundant lipid from each class has been detected. In addition, DESI was able to detect a range of other lipids including cholesterol, ceramide, ceramide-1-phosphates, glycolipids and lyso 1-O-alkyl phosphatidylethanolamines as $[\mathrm{M}+\mathrm{H}]^{+}$ions thus giving a comprehensive overview of the lens tissue lipodome in a single analysis. In contrast, direct MALDI analysis of human lenses by Deeley et al. [11] revealed only the presence of several abundant sphingomyelins, the corresponding ceramides and dehydrated cholesterol, while in another study direct MALDI analysis of

Table 2. Lens lipids detected by DESI-MS in positive ion mode. All lipids are observed as $[\mathrm{M}+\mathrm{H}]^{+}$ions with the exception of cholesterol, which is observed as [Chol + $\left.\mathrm{H}-\mathrm{H}_{2} \mathrm{O}\right]^{+}$. Lipid assignments are based on previous observations as described in references $[3,4,37,39,40]$

\begin{tabular}{ll}
\hline$m / z$ & \multicolumn{1}{c}{ Assigned Lipid } \\
\hline \hline $369^{\mathrm{b}}$ & {$\left[\text { Chol }+\mathrm{H}-\mathrm{H}_{2} \mathrm{O}\right]^{+}$} \\
440 & {$[\mathrm{LPE}(16: 0 \mathrm{e})+\mathrm{H}]^{+}$} \\
466 & {$[\mathrm{LPE}(18: 1 \mathrm{e})+\mathrm{H}]^{+}$} \\
538 & {$[\text { Cer }(\mathrm{d} 18: 1 / 16: 0)+\mathrm{H}]^{+}$} \\
540 & {$[\text { Cer }(\mathrm{d} 18: 0 / 16: 0)+\mathrm{H}]^{+}$} \\
618 & {$[\text { Cer1P }(\mathrm{d} 18: 1 / 16: 0)+\mathrm{H}]^{+}$} \\
620 & {$[\text { Cer1P }(\mathrm{d} 18: 0 / 16: 0)+\mathrm{H}]^{+}$} \\
648 & {$[\text { Cer }(18: 1 / 24: 1)+\mathrm{H}]^{+}$} \\
650 & {$[\text { Cer }(\mathrm{d} 18: 0 / 24: 1)+\mathrm{H}]^{+}$} \\
675 & {$[\mathrm{SM}(\mathrm{d} 18: 1 / 14: 0)+\mathrm{H}]^{+}$} \\
677 & {$[\mathrm{SM}(\mathrm{d} 18: 0 / 14: 0)+\mathrm{H}]^{+}$} \\
$703^{\mathrm{c}}$ & {$[\mathrm{SM}(\mathrm{d} 18: 1 / 16: 0)+\mathrm{H}]^{+}$} \\
$704^{\mathrm{c}}$ & {$[\mathrm{PE}(16: 0 \mathrm{e} / 18: 1)+\mathrm{H}]^{+}$} \\
$705^{\mathrm{c}}$ & {$[\mathrm{SM}(\mathrm{d} 18: 0 / 16: 0)+\mathrm{H}]^{+}$} \\
$730^{\mathrm{b}, \mathrm{c}}$ & {$[\mathrm{PE}(18: 1 \mathrm{e} / 18: 1)+\mathrm{H}]^{+}$} \\
& {$[\mathrm{Cer} 1 \mathrm{P}(\mathrm{d} 18: 0 / 24: 1)+\mathrm{H}]^{+}$} \\
$748^{\mathrm{c}}$ & {$[\mathrm{PS}(16: 0 \mathrm{e} / 18: 1)+\mathrm{H}]^{+}$} \\
$760^{\mathrm{c}}$ & {$[\mathrm{PC}(16: 0 / 18: 1)+\mathrm{H}]^{+}$} \\
$774^{\mathrm{c}}$ & {$[\mathrm{PS}(18: 1 \mathrm{e} / 18: 1)+\mathrm{H}]^{+}$} \\
776 & {$[\mathrm{PS}(18: 0 \mathrm{e} / 18: 1)+\mathrm{H}]^{+}$} \\
$787^{\mathrm{c}}$ & {$[\mathrm{SM}(\mathrm{d} 18: 1 / 22: 0)+\mathrm{H}]^{+}$} \\
789 & {$[\mathrm{SM}(\mathrm{d} 18: 0 / 22: 0)+\mathrm{H}]^{+}$} \\
$813^{\mathrm{c}}$ & {$[\mathrm{SM}(18: 1 / 24: 1)+\mathrm{H}]^{+}$} \\
$815^{\mathrm{c}}$ & {$[\mathrm{SM}(\mathrm{d} 18: 0 / 24: 1)+\mathrm{H}]^{+}$} \\
$864^{\mathrm{a}}$ & {$[\mathrm{LacCer}(\mathrm{d} 18: 0 / 16: 0)+\mathrm{H}]^{+}$} \\
$974^{\mathrm{a}}$ & {$[\mathrm{LacCer}(\mathrm{d} 18: 0 / 24: 1)+\mathrm{H}]^{+}$} \\
\hline &
\end{tabular}

aThe sugar units here are named as lactose based on the literature precedent that glycolipids containing a glucose and galactose sugar unit are the most abundant species. The sugar composition was not characterized in this investigation and thus the presence of isomeric sugar groups cannot be excluded.

${ }^{b}$ Confirmed by CID.

${ }^{\mathrm{c} C o n f i r m e d ~ b y ~ e x a c t ~ m a s s ~ m e a s u r e m e n t s . ~}$ porcine lenses revealed only sphingomyelins and 2 ceramide-1-phosphates [10]. Furthermore under the DESI conditions used in this investigation, all lipids with the exception of cholesterol were observed as [M + $\mathrm{H}^{+}$ions unlike the previous direct tissue MALDI investigations $[10,11]$ where many lipids were observed as $[\mathrm{M}+\mathrm{H}]^{+},[\mathrm{M}+\mathrm{Na}]^{+}$, and $[\mathrm{M}+\mathrm{K}]^{+}$ions, leading to an overall loss in sensitivity.

\section{DESI-Imaging of Lens Lipids}

Figure 3 shows the abundance distributions of a range of ionized lipids and cholesterol within a 41-y-old lens (additional images from 23-, 50-, and 55-y-old lenses are provided as Supporting Information, which can be found in the electronic version of this article). The intensity scales on the images indicate the upper and lower intensity threshold values used to generate the false color plot. The $[\mathrm{M}+\mathrm{H}]^{+}$ions from SM (d18:0/ 16:0) and SM (d18:0/24:1) are more abundant in the outer and barrier regions of the lens, which is in agreement with our previous MALDI-imaging and sectioning studies of human lenses [11]. The most abundant 1-O-alkyl phospholipid in the human lens corresponds to PE (18:1e/18:1) with an $[\mathrm{M}+\mathrm{H}]^{+}$ion at $\mathrm{m} / \mathrm{z}$ 730 . The distribution of the $m / z 730$ suggests this lipid is predominantly distributed in a thin ring $\sim 1-1.5 \mathrm{~mm}$ thick in the outer region of the lens. While the $\mathrm{m} / \mathrm{z} 730$ ion will also have a small component due to the isobaric $[\text { Cer1P }(\mathrm{d} 18: 0 / 24: 1)+\mathrm{H}]^{+}$(Table 1) it is dominated by [PE $(18: 1 / 18: 1)+\mathrm{H}^{+}$(see earlier). The related [PS $(18: 1 \mathrm{e} / 18: 1)+\mathrm{H}]^{+}$lipid is shown to have an identical distribution to that of the PE ether. Although this ion is present in low abundance in the mass spectra, the exact mass measurements (Table 1), the fact that it has previously been identified in human lens tissue by ESI-MS as PS (18:1e/18:1) [4] and that it has an identical distribution to the related PE (18:1e/18:1) supports the assignment of this ion as [PS $(18: 1 \mathrm{e} / 18: 1)+\mathrm{H}^{+}$. The co-localization of these two lipids could arise from the inter-conversion between the two in vivo. Biologically it is possible to synthesize PE via decarboxylation of PS, while PS lipids can be synthesized by the action of phosphatidylserine synthase II on PE [41]. All other low abundance 1-O-alkyl PE and PS lipids between $\mathrm{m} / \mathrm{z}$ 730-800 were also observed to have a distribution identical to that of PE (18:1e/18:1). Cholesterol (observed as the dehydrated form) was the most abundant lipid detected from the lens tissue and appears to be distributed homogenously throughout the lens with the exception of lower signal observed in the inner-most region. It is also possible that this is an artifact of the DESI process due to inefficient desorption of lipids from this region. To investigate this possibility, MALDI data acquired for a previous study [11] was re-analyzed and the distribution of $\mathrm{m} / \mathrm{z} 369$ was found to be consistent with that in Figure $3 d$ (data not shown). The congruence of these two independent desorption/ionization approaches provides strong evidence for the 


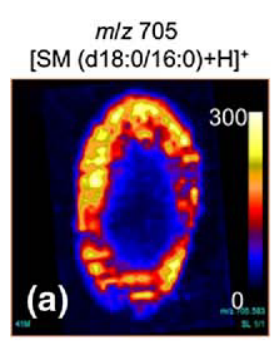

$m / z 815$ $[\mathrm{SM}(\mathrm{d} 18: 0 / 24: 1)+\mathrm{H}]^{+}$

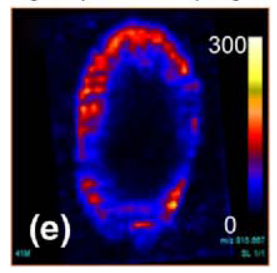

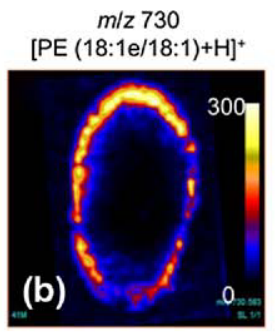

$m / z 774$

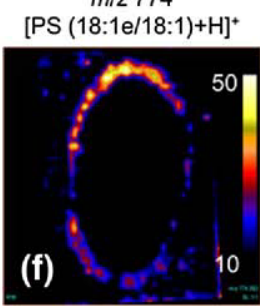

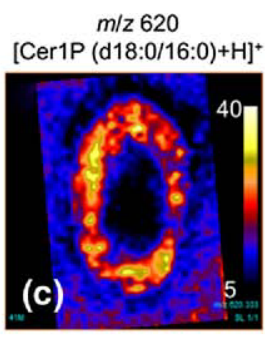

$\mathrm{m} / \mathrm{z} 540$

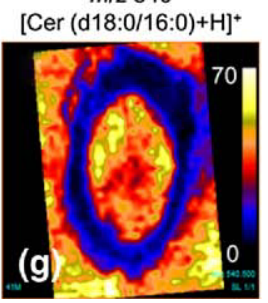

$m / z 369$ $\left[\mathrm{Chol}+\mathrm{H}-\mathrm{H}_{2} \mathrm{O}\right]^{+}$

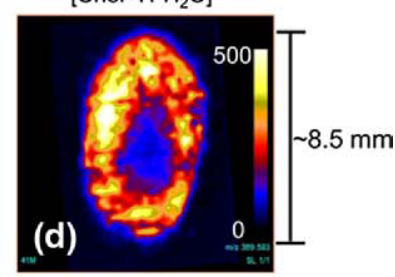

$m / z 466$ $[\operatorname{LPE}(18: 1 e)+\mathrm{H}]^{+}$

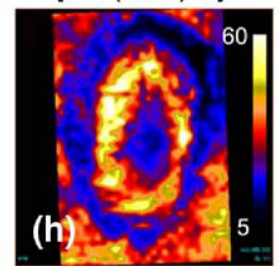

Figure 3. DESI images from a $41 \mathrm{y}$-old human lens illustrating the distribution of (a) [SM $(\mathrm{d} 18: 0 / 16: 0)+\mathrm{H}]^{+},(\mathbf{b})[\mathrm{PE}(18: 1 \mathrm{e} / 18: 1)+\mathrm{H}]^{+}$, (c) $[\mathrm{Cer1P}(\mathrm{d} 18: 0 / 16: 0)+\mathrm{H}]^{+}$, (d) $\left[\mathrm{Chol}+\mathrm{H}-\mathrm{H}_{2} \mathrm{O}\right]^{+}$, (e) $[\mathrm{SM}(\mathrm{d} 18: 0 / 24: 1)+\mathrm{H}]^{+}$, (f) $[\mathrm{PS}(18: 1 \mathrm{e} / 18: 1)+\mathrm{H}]^{+},(\mathrm{g})[\mathrm{Cer}(\mathrm{d} 18: 0 / 16: 0)+\mathrm{H}]^{+}$, and (h) $[\mathrm{LPE}$ $(18: 1 \mathrm{e})+\mathrm{H}]^{+}$. The colored bar in each image represents an arbitrary intensity scale used to define each image. The oval appearance of these images arises from a slight compression of the lens during slicing; this, however, does not affect the relative dimensions used to define each region.

conclusion that there exists a lower concentration of cholesterol in the lens centre. This is further supported by lens sectioning studies [42] that indicate this decrease is also accompanied by an increase in the cholesterol-to-phospholipid ratio [42, 43] consistent with the DESI-based observation of decreased phospholipid abundances in the lens centre.

Analysis of the DESI mass spectra shows a broad distribution of noise in the $m / z 450-700$ range when the spray solution came in contact with the glass slide (see Figure $1 \mathrm{~d}$ and Figure $4 \mathrm{a}$ ). The intensity of this noise was similar to that of the signal arising from ionized ceramides, ceramide-1-phosphates and lyso phosphatidylethanolamines observed in this mass range. This broad noise feature complicates the image by showing apparent ion intensity when analyzing regions away from the lens tissue as observed in the DESI images for $\left.[\mathrm{Cer1P}(\mathrm{d} 18: 0 / 16: 0)+\mathrm{H}]^{+},{ }, \mathrm{Cer}(\mathrm{d} 18: 0 / 16: 0)+\mathrm{H}\right]^{+}$and $[\operatorname{LPE}(18: 1 \mathrm{e})+\mathrm{H}]^{+}$(see Figure $3 \mathrm{c}, \mathrm{g}$, and $\mathrm{h}$ ). The occurrence of this broad distribution of noise was encountered throughout the investigation and the exact origin is unknown although it appears to be an artifact caused by the addition of acid. When methanol:water mixtures not containing acid were used the noise was not present, however this also resulted in very few, if any, lipids being detected. The noise was also only present when the spray was positioned off the lens tissue, i.e.; on the glass slide, leading us to believe the noise was due to an interaction between the acid and the glass slide. The noise could be reduced by increasing the tube lens voltage, however this also significantly decreased lipid ion abundances. Figure 4 shows spectra in the $m / z$ 400-550 range plotted on absolute intensity scales obtained from (a) a single line scan when the spray was positioned on the glass slide adjacent to the lens and (b) on the lens tissue itself. These data clearly show that when positioned away from the lens there was no detection of $m / z$ 440, 466, 538 and 540 (see Table 2 for peak assignments), however, the broad distribution of noise in this range resulted in false detection when creating distribution images for these ions. When positioned on the lens tissue, distinct ions were observed and the background noise was significantly reduced. Therefore, any signal observed outside of the lens tissue can be ignored. Accordingly, distinct distributions are observed for protonated Cer (d18:0/16:0) and Cer1P (d18:0/16:0) in Figure 3. [Cer (d18:0/16:0) + $\mathrm{H}^{+}$is observed to be concentrated in the nucleus (core region) of the lens, consistent with previous MALDIimaging data [11]. An identical distribution is also observed for the protonated forms of Cer (d18:0/24:1), Cer (d18:1/16:0) and Cer (d18:1/24:1) (data not shown). The observed ceramides have the same sphingosine/ sphinganine base and fatty amide structures as the corresponding sphingomyelins. This suggests the ceramides could be produced via hydrolysis of the SM headgroups, however if this is the case the mechanism by which the ceramides appear in the centre of the lens is as yet unknown. The related ceramide-1-phosphates differ from ceramides by the presence of a phosphate headgroup. The localization of [Cer1P (d18:0/16:0) + $\mathrm{H}^{+}$is shown in Figure $3 \mathrm{c}$ and reveals an annular distribution with the regions of highest abundances observed at the transition from the inner to the outer portions of the lens. Low ion counts from this lipid were measured in the lens center, which stands in contrast to the distribution of the related ceramide, [Cer (d18:0/16:0) $+\mathrm{H}]^{+}$(Figure 3g). While the distribution of [Cer1P 

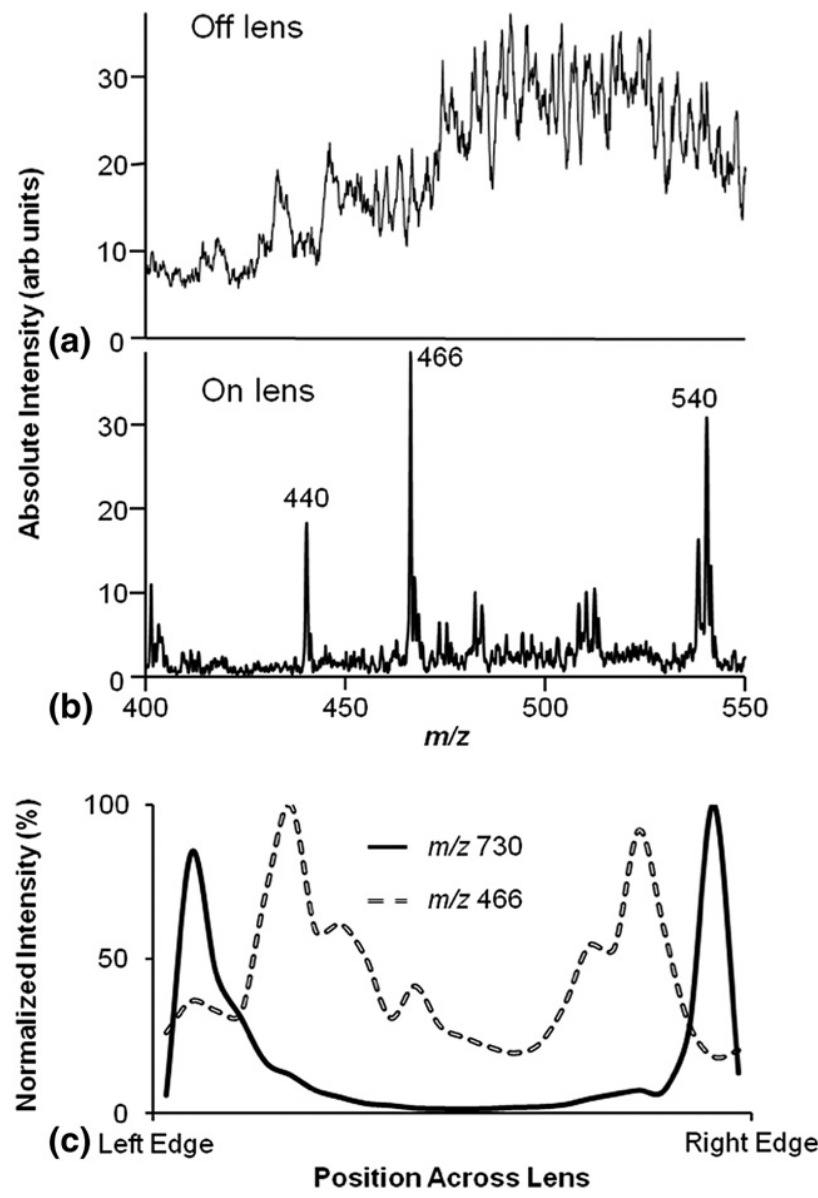

Figure 4. DESI mass spectra acquired from a line scan cross a 41-y old lens when the spray is positioned (a) on the glass slide adjacent to lens tissue and (b) on the lens tissue itself. Note the broad distribution of artifact signal when the spray is positioned over the glass slide. As the spray is positioned over the lens tissue the noise reduces significantly and well-defined ion signals can be observed. (c) Plot of normalized ion abundance of $\mathrm{m} / \mathrm{z} 730$ ([PE $\left.(18: 1 \mathrm{e} / 18: 1)+\mathrm{H}]^{+}\right)$and $m / z 466\left([\operatorname{LPE}(18: 1 \mathrm{e})+\mathrm{H}]^{+}\right.$across a 41 $y$-old lens slice. Note that the broad noise band [see (a)] will contribute some intensity to the $m / z 466$ channel, particularly at the edges of the lens slice.

$(\mathrm{d} 18: 0 / 16: 0)+\mathrm{H}]^{+}$is more similar to that of [SM (d18:0/ 16:0) $+\mathrm{H}^{+}$(Figure 3a), the former appears to be distributed slightly closer to the nucleus while the latter displays maximum ion abundances further from the lens center. Distributions of the other protonated ceramide-1phosphates detected in this study, namely Cer1P (d18:1/ 16:0) and Cer1P (d18:1/24:1) (data not shown) were found to be similar to that of $[\mathrm{Cer1P}(\mathrm{d} 18: 0 / 16: 0)+\mathrm{H}]^{+}$. As discussed previously, determining the distribution of the corresponding [Cer1P $(\mathrm{d} 18: 0 / 24: 1)+\mathrm{H}]^{+}$is difficult due to it being isobaric with the more abundant [PE (18:1e/ $18: 1)+\mathrm{H}]^{+}$but it might be expected to be similar to that of [Cer1P (d18:0/16:0) $+\mathrm{H}]^{+}$.

An interesting distribution was observed for [LPE $(18: 1 \mathrm{e})+\mathrm{H}]^{+}(\mathrm{m} / \mathrm{z} 466)$ (Figure 3h). [LPE $\left.(18: 1 \mathrm{e})+\mathrm{H}\right]^{+}$ displayed an annular distribution that is concentrated "inside" that of the protonated PE (18:1e/18:1). Figure $4 \mathrm{c}$ shows a plot of the normalized ion intensities ob- tained from a single line scan for the protonated forms of PE (18:1e/18:1) (m/z 730) and LPE (18:1e) $(\mathrm{m} / \mathrm{z} 466)$ across a 41-y-old lens section. The plot clearly shows that the maximum ion intensity for [LPE (18:1e)] occurs slightly "inside" that of [PE (18:1e/18:1) $+\mathrm{H}]^{+}$. An identical relationship is also observed for [PE (16:0e/ 18:1) $+\mathrm{H}]^{+}$and $[\operatorname{LPE}(16: 0 \mathrm{e})+\mathrm{H}]^{+}$at $m / z 704$ and 440 , respectively. It is possible that LPE (18:1e) could be produced via hydrolysis of the acyl 18:1 fatty acid in PE (18:1e/18:1). In addition, loss of ester-linked fatty acids from other PE (18:1e) phospholipids, previously found at lower abundance in the human lens [3], could also produce LPE (18:1e). The distinct distribution of LPE (18:1e) with respect to its most abundant progenitor PE (18:1e/18:1) excludes the possibility that acid hydrolysis is occurring during the DESI process (see Figure 4). This leaves open the possibility of conversion occurring in vivo either by enzymatic or chemical pathways.

\section{Regional Quantification of PE (18:1e/18:1)}

A general limitation of mass spectrometric imaging techniques is the question of whether the generated image for the ionized species is representative of the molecular distributions in the sample. This question arises due to the occurrence of ion suppression effects as well as sample variability such as changes in the height profile and tissue composition that may affect the detection of analytes from different areas of a tissue section $[9,44]$. Thus, the observed ion abundance may not necessarily reflect the absolute amount of a particular lipid in a given area but rather the ease with which it can be desorbed from the tissue [9]. In this study, DESI-images of the $[\mathrm{M}+\mathrm{H}]^{+}$ion arising from PE (18:1e/18:1) suggest an annular distribution of the lipid within the outer regions of the lens. This image was observed for lens sections from a $41 \mathrm{y}$-old individual (Figure $3 b$ ) and was found to be reproducible in lens sections from both younger and older individuals (example images from 28, 50 and 55 y-old individuals are provided as Supporting Information). To determine whether the observed distribution of the $m / z 730$ ion assigned to [PE $(18: 1 \mathrm{e} / 18: 1)+\mathrm{H}]^{+}$is representative of the distribution of the lipid in the lens, two additional lenses from 52- and 75-y-old individuals were dissected into outer, barrier, inner, and core sections and the lipids extracted and quantified by ESI-MS. Figure 5 shows the concentration of PE (18:1e/18:1) in each lens section determined by ESI-MS along with an extracted ion chromatogram for the $m / z 730$ ion from a line scan across the $41-y$-old lens slice by DESI-MS. The bottom axes are positioned to represent the relative distance between the four regions of the lens. The regional concentrations determined by ESI-MS match closely the relative abundances determined by DESI-MS, providing strong evidence that the spatial and intensity distributions determined by DESI-MS imaging are representative of the lipid distribution in the lens. 


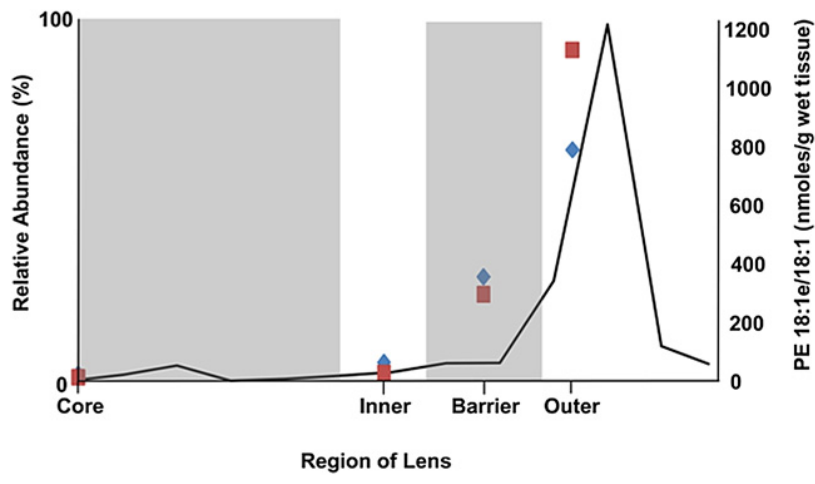

Figure 5. Plot of ion abundance from a $41 \mathrm{y}$-old lens of PE (18:1e/18:1) from a DESI-MS line scan across the lens tissue (black line) and data obtained from sectioning and quantification by ESI-MS from a 52- (filled diamond) and 75- (filled square) year old lens. The $\mathrm{x}$-axis labels are scaled according to their relative position in the lens and each the areas of each adjacent section shaded (refer to schematic in Figure 1).

\section{Conclusions}

DESI has previously been reported as an effective method for the analysis and imaging of lipids directly from tissue $[19,20,24]$. In the present study, we have applied this technique to the analysis of human lens lipids and made several interesting discoveries. Unlike other tissues previously analyzed by DESI, lipids could not be desorbed from lens slices without the presence of a strong acid in the spray solution. As mentioned above, this may be due to the tightly-packed laminae of fiber cells, their high protein content, and/or the strength of protein-lipid interactions within cellular membranes. Importantly, the most abundant lipids identified in the current DESI analysis, e.g.; cholesterol, DHSM, and 1-O-alkyl linked PEs, are consistent with previous studies using various MS and NMR techniques [3, 4, 37, 45]. There is also strong agreement between the distribution of $[\mathrm{PE}(18: 1 \mathrm{e} / 18: 1)+\mathrm{H}]^{+}$ions obtained from direct DESI analysis and the quantitative measurements obtained from dissection and extraction experiments (see Figure 5). Moreover, the distribution of [SM (d18:0/ 16:0) $+\mathrm{H}]^{+}$and $[\mathrm{Cer}(\mathrm{d} 18: 0 / 16: 0)+\mathrm{H}]^{+}$ions observed in the current study agree with previous findings from MALDI-imaging [11]. When taken in concert, these findings suggest that ion distributions obtained by DESI analysis of lens slices are representative of lipid abundance and distribution in the human lens. In contrast to MALDI, which requires the deposition of different matrices to detect different lipid classes, DESI provides the advantage of being able to detect all major lens lipids in a single scan.

In applying DESI-imaging to the human lens, we were able to provide the first spatial distribution analysis of PE (18:1e/18:1): the most abundant glycerophospholipid in the human lens. Interestingly, this and other 1-O-alkyl ether lipids were found to exist predominantly in the outer, metabolically active region of the lens, while lyso 1-O-alkyl species were observed pri- marily in the adjacent inner region. This suggests that 1-O-alkyl ether lipids are actively synthesized in the epithelium and emerging fiber cells and that the esterlinked fatty acid is cleaved or hydrolyzed as fiber cells mature. It should be noted that the composition and distribution of human lens lipids is altered dramatically with age $[11,46]$ and that the lipid distributions observed in the current study may differ from those obtained from lenses of different ages. Indeed, DESIimages obtained in this study for lens sections from 28 and 50 and $55 \mathrm{y}$-old individuals (Supporting Information) suggest greater abundances of [Cer (d18:0/16:0) + $\mathrm{H}]^{+}$ions arising from the inner region of the lens with increasing age. The preliminary observation of such age-related trends by MALDI- and now DESI-based imaging provides a clear motivation for future quantitative studies of these effects.

\section{Acknowledgments}

S.R.E. is supported by an Australian Postgraduate Award and the University of Wollongong Faculty of Science travel award. S.J.B. and T.W.M. acknowledge the financial support of the University of Wollongong and the Australian Research Council (LP0989883 and DP0986628). M. in het P. is supported by an ARC Future Fellowship (FT09908). R.J.W.T. is a National Health and Medical Research Fellow and acknowledges the financial support of the National Health and Medical Research Council (512334) and the Ophthalmic Research Institute of Australia. R.G.C. acknowledges financial support from the National Science Foundation CHE 0848650 .

\section{Appendix A \\ Supplementary Material}

Supplementary material associated with this article may be found in the online version at doi:10.1016/ j.jasms.2010.09.003.

\section{References}

1. Forrester, J. V.; Dick, A. D.; McMenamin, P. G.; Roberts, F. The Eye: Basic Science in Practice; Saunders Elsevier: Philadelphia, 2008; pp 228-236.

2. Byrdwell, W. C.; Borchman, D.; Porter, R. A.; Taylor, K. G.; Yappert, M. C. Separation and Characterization of the Unknown Phospholipid in Human Lens Membranes. Invest. Ophthalmol. Vis. Sci. 1994, 35, 43334343.

3. Deeley, J. M.; Mitchell, T. W.; Wei, X.; Korth, J.; Nealon, J. R.; Blanksby, S. J.; Truscott, R. J. W. Human Lens Lipids Differ Markedly From Those of Commonly Used Experimental Animals. Biochim. Biophys. Acta, Mol. Cell. Biol. Lipids. 2008, 1781, 288-298.

4. Deeley, J. M.; Thomas, M. C.; Truscott, R. J. W.; Mitchell, T. W.; Blanksby, S. J. Identification of Abundant Alkyl Ether Glycerophospholipids in the Human Lens by Tandem Mass Spectrometry Techniques. Anal. Chem. 2009, 81, 1920-1930.

5. Merchant, T. E.; Lass, J. H.; Meneses, P.; Greiner, J. V.; Glonek, T. Human Crystalline Lens Phospholipid Analysis with Age. Invest. Ophthalmol. Vis. Sci. 1991, 32, 549-555.

6. Yappert, M. C.; Rujoi, M.; Borchman, D.; Vorobyov, I.; Estrada, R. Glycero- Versus Sphingophospholipids: Correlations with Human and Nonhuman Mammalian Lens Growth. Exp. Eye Res. 2003, 76, 725-734.

7. Rujoi, M.; Estrada, R.; Yappert, M. C. In Situ MALDI-TOF MS Regional Analysis of Neutral Phospholipids in Lens Tissue. Anal. Chem. 2004, 76, 1657-1663.

8. Petkovic, M.; Schiller, J.; Müller, M.; Benard, S.; Reichl, S.; Arnold, K.; Arnhold, J. Detection of Individual Phospholipids in Lipid Mixtures by Matrix-Assisted Laser Desorption/Ionization Time-of-Flight Mass Spectrometry: Phosphatidylcholine Prevents the Detection of Further Species. Anal. Biochem. 2001, 289, 202-216. 
9. Murphy, R. C.; Hankin, J. A.; Barkley, R. M. Imaging of Lipid Species by MALDI Mass Spectrometry. J. Lipid Res. 2009, 50, S217-S322.

10. Vidova, V.; Pol, J.; Volny, M.; Novak, P.; Havlicek, V.; Wiedmer, S. K.; Holopainen, J. M. Visualizing Spatial Lipid Distribution in Porcine Lens by MALDI Imaging High-Resolution Mass Spectrometry. J. Lipid Res. 2010, 51, 2295-2302

11. Deeley, J. M.; Hankin, J. A.; Friedrich, M. C.; Murphy, R. C.; Truscott, R. J. W.; Blanksby. S. J.; Mitchell, T. W. Sphingolipid Distribution Changes with Age in the Human Lens. J. Lipid Res. 2010, 51, 2753-2760.

12. Thibault, D. B.; Gillam, C. J.; Grey, A. C.; Han, J.; Schey, K. L. MALDI Tissue Profiling of Integral Membrane Proteins from Ocular Tissues. J. Am. Soc. Mass Spectrom. 2008, 19, 814-822.

13. Grey, A. C.; Schey, K. L. Age-Related Changes in the Spatial Distribution of Human Lens $\alpha$-Crystallin Products by MALDI Imaging Mass Spectrometry. Invest. Ophthalmol. Vis. Sci. 2009, 50, 4319-4329.

14. Grey, A. C.; Schey, K. L. Distribution of Bovine and Rabbit Lens $\alpha$-Crystallin Products by MALDI Imaging Mass Spectrometry. Mol. Vis. 2008, 14, 171-179

15. Han, J.; Schey, K. L. MALDI Tissue Imaging of Ocular Lens $\alpha$-Crystallin. Invest. Ophthalmol. Vis. Sci. 2006, 47, 2990-2996.

16. Hankin, J. A.; Barkley, R. M.; Murphy, R. C. Sublimation as a Method of Matrix Application for Mass Spectrometric Imaging. J. Am. Soc. Mass Spectrom. 2007, 18, 1646-1652.

17. Cooks, R. G.; Ouyang, Z.; Takats, Z.; Wiseman, J. M. Ambient Mass Spectrometry. Science 2006, 311, 1566-1570.

18. Zoltan, T.; M, W.; Bodgan, G.; Cooks, R. G. Mass Spectrometry Sampling Under Ambient Conditions with Desorption Electrospray Ionization. Science 2004, 306, 471-473.

19. Ifa, D. R.; Wiseman, J. M.; Song, Q.; Cooks, R. G. Development of Capabilities for Imaging Mass Spectrometry Under Ambient Conditions with Desorption Electrospray Ionization (DESI). Int. J. Mass Spectrom. 2007, 259, 8-15.

20. Dill, A. L.; Ifa, D. R.; Manicke, N. E.; Costa, A. B.; Ramos-Vara, J. A.; Knapp, D. W.; Cooks, R. G. Lipid Profiles of Canine Invasive Transitional Cell Carcinoma of the Urinary Bladder and Adjacent Normal Tissue by Desorption Electrospray Ionization Imaging Mass Spectrometry. Anal. Chem. 2009, 81, 8758-8764.

21. Manicke, N. E.; Wiseman, J. M.; Ifa, D. R.; Cooks, R. G. Desorption Electrospray Ionization (DESI) Mass Spectrometry and Tandem Mass Spectrometry (MS/MS) of Phospholipids and Sphingolipids: Ionization, Adduct Formation, and Fragmentation. J. Am. Soc. Mass Spectrom. 2008, 19, 531-543.

22. Wu, C.; Ifa, D. R.; Manicke, N. E.; Cooks, R. G. Rapid, Direct Analysis of Cholesterol by Charge Labeling in Reactive Desorption Electrospray Ionization. Anal. Chem. 2009, 81, 7618-7624.

23. Blanksby, S. J.; Mitchell, T. W. Advances in Mass Spectrometry for Lipidomics. Annu. Rev. Anal. Chem. 2010, 3, 433-465

24. $\mathrm{Wu}, \mathrm{C}$.; Ifa, D. R.; Manicke, N. E.; Cooks, R. G. Molecular Imaging of Adrenal Gland by Desorption Electrospray Ionization Mass Spectrometry. Analyst 2010, 135, 28-32.

25. Wiseman, J. M.; Ifa, D. R.; Venter, A.; Cooks, R. G. Ambient Molecular Imaging by DESI-MS. Nature Protocols 2008, 3, 517-524.

26. Wiseman, J. M.; Ifa, D. R.; Zhu, Y.; B, K. C.; Manicke, N. E.; Kissinger, P. T.; Cooks, R. G. Desorption Electrospray Ionization Mass Spectrometry: Imaging Drugs and Metabolites in Tissues. Proc. Nat. Acad. Sci. U.S.A. 2008, 105, 18120-18125.

27. Manicke, N. E.; Kistler, T.; Ifa, D. R.; Cooks, R. G.; Ouyang, Z. High-Throughput Quantitative Analysis by Desorption Electrospray
Ionization Mass Spectrometry. J. Am. Soc. Mass Spectrom. 2009, 20, 321-325.

28. Heys, K. R.; Friedrich, M. G.; Truscott, R. J. W. Free and Bound Water in Normal and Cataractous Human Lenses. Invest. Ophthalmol. Vis. Sci. 2008, 49, 1991-1997.

29. Folch, J.; Lees, M.; Stanley, G. H. S. A Simple Method For The Isolation and Purification of Total Lipids from Animal Tissues. J. Biol. Chem. 1957, 226, 497-509.

30. Wiseman, J. M.; Ifa, D. R.; Song, Q.; Cooks, R. G. Tissue Imaging at Atmospheric Pressure Using Desorption Electrospray Ionization (DESI) Mass Spectrometry. Angew. Chem.; Int. Ed. 2006, 45, 7188-7192.

31. Manicke, N. E.; Nefliu, M.; Wu, C.; Woods, J. W.; Reiser, V.; Hendrickson, R. C.; Cooks, R. G. Imaging of Lipids in Atheroma by Desorption Electrospray Ionization Mass Spectrometry. Anal. Chem. 2009, 81, 87028707.

32. Zigman, S.; Paxhia, T.; Marinetti, G.; Girsch, S. Lipids of Human Lens Fiber Cell Membranes. Curr. Eye Res. 1984, 3, 887-896.

33. Lapetina, E. G.; Soto, E. F.; Robertis, E. D. Lipids and Proteolipids in Isolated Subcellular Membranes of Rat Brain Cortex. J. Neurochem. 1968, 15, 437-445.

34. Gonen, T.; Cheng, Y.; Sliz, P.; Hiroaki, Y.; Fujiyoshi, Y.; Harrison, S. C.; Walz, T. Lipidprotein interactions in double-layered two-dimensional AQP0 crystals. Nature 2005, 438, 633-638.

35. Fagerholm, P. P.; Philipson, B. T.; Lindström, B. Normal Human Lens-The Distribution of Protein. Exp. Eye Res. 1981, 33, 615-620.

36. DePuy, C. H.; King, R. W. Pyrolytic cis Eliminations. Chem. Rev. 1960, 60, 431-457.

37. Estrada, R.; Puppato, A.; Borchman, D.; Yappert, M. C. Reevaluation of the Phospholipid Composition in Membranes of Adult Human Lenses by ${ }^{31} \mathrm{P}$ NMR and MALDI MS. Biochim. Biophys. Acta, Biomembr. 2010, $1798,303-311$.

38. Thomas, M. C.; Mitchell, T. W.; Harman, D. G.; Deeley, J. M.; Nealon, J. R.; Blanksby, S. J. Ozone-Induced Dissociation: Elucidation of Double Bond Position within Mass-Selected Lipid Ions. Anal. Chem. 2007, 80, 303-311.

39. Ariga, T.; Tao, R. V.; Lee, B. C.; Yamawaki, M.; Yoshino, H.; Scarsdale, N. J.; Kasama, T.; Kushi, Y.; Yu, R. K. Glycolipid Composition of Human Cataractous Lenses. Characterization of Lewis-X Glycolipids. J. Biol. Chem. 1994, 269, 2667-2675.

40. Ogiso, M.; Irie, A.; Kubo, H.; Komoto, M.; Matsuno, T.; Koide, Y.; Hoshi, M. Characterization of Neutral Glycosphingolipids in Human Cataractous Lens. J. Biol. Chem. 1993, 268, 13242-13247.

41. Gurr, M. I.; Harwood, J. L.; Fraym, K. N. Lipid Biochemsitry, an Introduction; Blackwell Science: Oxford, p. 275

42. Li, L. K.; So, L.; Spector, A. Membrane Cholesterol and Phospholipid in Consecutive Concentric Sections of Human Lenses. J. Lipid Res. 1985, 26, 600-609.

43. Roy, D.; Rosenfeld, L.; Spector, A. Lens Plasma Membrane: Isolation and Biochemical Characterization. Exp. Eye Res. 1982, 35, 113-129.

44. Heeren, R. M. A.; Smith, D. F.; Stauber, J.; Kükrer-Kaletas, B.; MacAleese, L. Imaging Mass Spectrometry: Hype or Hope? J. Am. Soc. Mass Spectrom. 2009, 20, 1006-1014.

45. Rujoi, M.; Jin, J.; Borchman, D.; Tang, D. Yappert, M. C. Isolation and Lipid Characterization of Cholesterol-Enriched Fractions in Cortical and Nuclear Human Lens Fibers. Invest. Ophthalmol. Vis. Sci. 2003, 44, 1634-1642.

46. Huang, L.; Grami, V.; Marrero, Y.; Tang, D.; Yappert, M. C.; Rasi, V.; Borchman, D. Human Lens Phospholipid Changes with Age and Cataract. Invest. Ophthalmol. Vis. Sci. 2005, 46, 1682-1689. 